\title{
Our experience in the treatment of priapism
}

\section{Dmytro Vorobets ${ }^{1}$, Oleg Banyra ${ }^{2}$, Alexander Stroy ${ }^{1}$, Alexander Shulyak ${ }^{1}$}

'Danylo Halytsky Lviv National Medical University, Lviv, Ukraine

${ }^{2} 2^{\text {nd }}$ Lviv Municipal Polyclinic, Lviv, Ukraine

\section{KEY WORDS}

priapism Dectile dysfunction D intracavernous injection D cavernoglanular shunting D

Winter shunt

\section{ABSTRACT}

Priapism is a persistent erection without sexual stimulation that cannot be relieved by orgasm. Its etiology includes the impaired mechanism of detumescence caused by the abundant release of neurotransmitters, venules obstruction, impairment of the intrinsic mechanism of detumescence, or prolonged relaxation of the intracavernous smooth muscles. Treatment of priapism is conservative, pharmacological, or surgical. Efficient treatment options include the intracavernous vasoconstrictor injections or surgical shunting. Alternative treatment options include the intracavernous methylene blue injections or selective penile arterial embolization. Between 2001 and 2009, we treated 10 patients with priapism at our clinic. According to our data, priapism as a complication after intracavernous administration of prostaglandin E1 occurs in 2.7\% of patients, after additional administration of prostaglandin E1 and phentolamine - in 5.0\% patients, after administration of papaverine - in $8.3 \%$ patients. The obtained results allow recommendation of prostaglandin E1 as a medication of choice among the vasoactive substances for intracavernous use due to high efficacy and low side effects. Initially all cases of priapism must be treated pharmaceutically, but can be converted to surgery as needed. Unilateral transcaputal puncture of the cavernous body (shunting after Winter) in our patients with ischemic priapism allowed to achieve detumescence in 100\% of cases without subsequent recurrence and to restore erectile function in $30 \%$ of patients.

\section{INTRODUCTION}

Priapism (Hulseyism) is a rare pathologic condition characterized by abnormally long-lasting, usually painful erections not accompanied by sexual stimulation and arousal [1]. The word "priapism" is derived from the Roman and Greek god Priapus, famous for his enormous, continuous erections. A special feature of priapism is that the erect penis does not spontaneously return to its flaccid state.

There are two types of priapism - ischemic, owing to weak blood supply, and non-ischemic, owing to abundant blood supply. Ischemic priapism can develop due to sickle-cell anemia, thalassemia, leukemia, anticoagulant intake, spinal injury, fat embolism, penile tumors, autonomic dysreflexia, and some pharmaceuticals. Rare incidents of priapism caused by antidepressant (trazodone) and antipsychotic (clozapine, chlorpromazine) drugs have been reported. It is necessary to remember a possibility of priapism appearance due to sildenafil, vardenafil, or tadalafil treatment. Nonischemic priapism with abundant blood supply most often develops as a result of perineal trauma and injuries of the penis. In such cases, the presence of a communication between the artery and cavernous bodies is typical, as result penis is filled with blood under intense pressure and blood cannot be drained adequately.

Many causes of priapism still remain unknown.

\section{OBJECTIVE}

To analyze the etiology of priapism, contemporary approaches to its management and efficacy of one-sided cavernoglanular shunting after Winter in ischemic priapism treatment.

\section{PATIENTS AND METHODS}

The study enrolled 10 patients with priapism who were treated at our urological clinic between 2001 and 2009. Their age ranged 22-71 years. In six patients priapism developed after erectile dysfunction treatment. In two patients priapism occurred as a consequence of systematic intake of anticoagulants (low-weight heparin) due to serious vascular pathology (phlebothrombosis, thrombophlebitis). In another two patients no objective cause of priapism was detected, therefore idiopathic disease was determined.

We analyzed the frequency of priapism incidences depending on prescribed medicines in 120 patients with erectile dysfunction (ED), who were treated by intracavernous injections. Among the 10 patients with priapism, six cases appeared as a complication of ED treatment. Priapism as a complication developed in two $(2.7 \%)$ among of 74 patients after intracavernous injection of 20 mcg of prostaglandin E1 (PGE-1), in 1 (5\%) of 20 patients after consequent administration of $20 \mathrm{mcg}$ of PGE-1 plus $0.5 \mathrm{mg}$ of phentolamine, and also in 3 (8.3\%) of 36 patients after administration of $2 \%$ papaverine solution. Patients in whom priapism developed after intracavernous injection of vasoactive substance, primarily reported to the sexological practice of Lviv Regional Consultative Ambulatory and the Chair of Urology of Danylo Halytsky Lviv National Medical University with complains of ED. All of them subsequently had a dopplerographic study of cavernous hemodynamics after pharmacological induction of erection for verification of the etiology of ED. The array of clinical and laboratory methods allowed to diagnose the primary cause of ED as psychogenic in all three patients with priapism after administration of PGE-1 solution. In three patients (aged 47, 51, and 58 years) with development of priapism due to injection of $2 \%$ papaverine solution, primary diagnosis was a mixed type of ED (a combination of psychogenic, vascular factors and manifestations of late hypogonadism). All patients with mixed ED were initially administered 0.7 $\mathrm{ml}$ of $2 \%$ papaverine solution, which did not cause an adequate erection and acceptable hemodynamic indices in the cavernous arteries (over $25 \mathrm{~cm} / \mathrm{sec}$ ), which is why 15 min after the first injection, 0.7 cc of $2 \%$ papaverine solution were administered to them additionally, which finally caused priapism. 
For the treatment of priapism initially we used intracavernous injections of E-adrenoreceptor agonists, but such therapy was ineffective. Afterwards all of 10 patients with verified priapism were injected by ketamine hydrochloride $1 \mathrm{mg} / \mathrm{kg}$ body mass IV in the operating room, and also peridural anesthesia was performed 2030 min later, which did not produce detumescence too. After that one-sided transcaputal punctures after Winter were performed (Fig. 1) in all patients, using a $16 \mathrm{G}$ needle (single-use IV catheter with an obturator was used) with heparin irrigation 5000-15000 IU during 30-45 minutes.

\section{RESULTS}

Results of treatment in 10 patients with priapism are presented in Table I.

In all of 10 patients shunting after Winter was effective in priapism elimination. It can be observed that in five cases the duration of priapism was insignificant (7-9 hours), since all patients were warned prior to injection of vasoactive substance about possible development of priapism and advised to seek immediately medical aid if this condition occurred. The short duration of priapism allowed to restore and to preserve the erectile function in all three patients with psychogenic erectile dysfunction, since there were no likely fibrotic changes in the cavernous tissue over 8 hours, and the difficulty of the intervention was insignificant. In three patients with a preliminary diagnosis of mixed erectile dysfunction (with an organic vascular component) it was not feasible to restore erectile function after shunting. The presence of endothelial dysfunction was possible in those patients prior to injection of a vasoactive substance, which necessitated seeking help for ED treatment. No other cases presented recurrences of priapism in the postoperative period. ED was not an actual problem for both patients receiving anticoagulant therapy. Both patients with idiopathic priapism reported absence of erections over several months of post-operative follow-up. Thus, it can be conferred that prolonged priapism often leads to irreversible dysfunction of endothelium with destructive and fibrotic changes in the cavernous tissue, which probably occur simultaneously [2]. Therefore, a retrospective review revealed a necessity to find new erection-safe methods for treatment of this disease.

\section{DISCUSSION}

There are such different therapeutic approaches to priapism treatment as mechanical (prolonged compression of perineum and application of ice packs), pharmacological (oral, intracavernous,

Table 1 . The results of treatment in patients with priapism

\begin{tabular}{|c|c|c|}
\hline $\begin{array}{c}\text { Number of Patients/ } \\
\text { Priapism-Inducing } \\
\text { Medication }\end{array}$ & $\begin{array}{c}\text { Age } \\
\text { (years) }\end{array}$ & $\begin{array}{c}\text { Duration of priapism } \\
\text { (hours) }\end{array}$ \\
\hline 1/ low-weight heparin & 71 & 35 \\
\hline 1/ low-weight heparin & 64 & 21 \\
\hline 1/ idiopathic priapism & 37 & 24 \\
\hline 1/ idiopathic priapism & 52 & 18 \\
\hline 1/ PGE-1 & 22 & 7 \\
\hline 1/ PGE-1 & 35 & 7 \\
\hline $1 /$ PGE-1+phentolamine & 26 & 7.5 \\
\hline $1 /$ papaverine & 47 & 25 \\
\hline 1/ papaverine & 51 & 9 \\
\hline 1/ papaverine & 58 & 8 \\
\hline
\end{tabular}

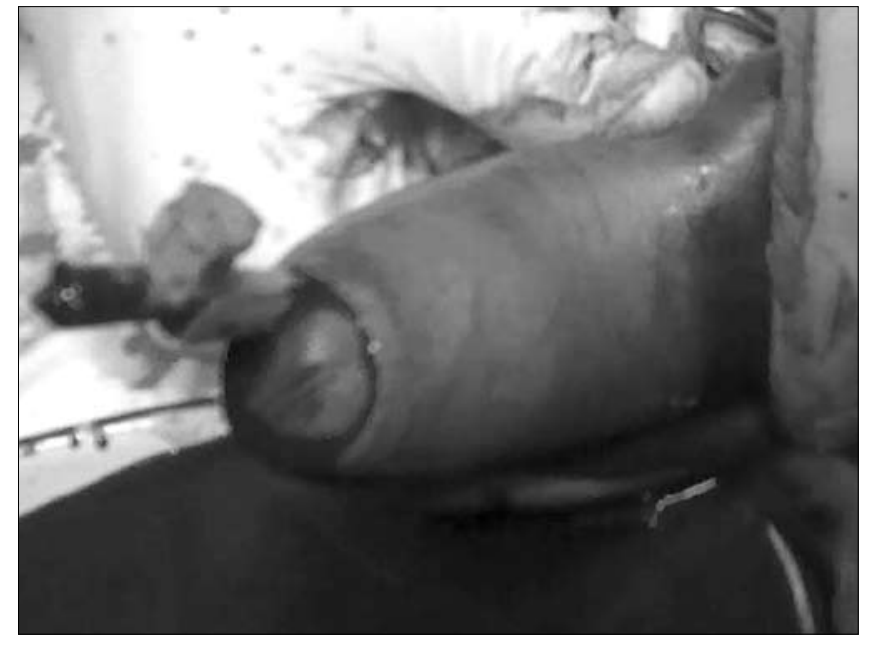

Fig. 1. One-sided transcaputal puncture after Winter.

and intravenous), radiological (selective embolization), and surgical (ligation of arteries or arteriovenous shunting) [3,4]. In contradistinction to non-ischemic priapism, which does not require immediate intervention, protracted ischemic priapism is always associated with progressive fibrosis of the cavernosal tissues and erectile dysfunction $[2,5]$. That is why all patients with priapism should be evaluated urgently in order to start treatment immediately in those patients with ischemic priapism. The aim of the treatment of all patients with priapism is to achieve detumescence as soon as possible to prevent future ED. In order to preserve erectile function, the first-line intervention should be mechanical and medical treatment (oral, intravenous, or intracavernous injections), following by a second-line shunting procedure if first-line fails $[3,6,7]$.

Some urologists have considered that oral administration of medications such as pseudoephedrine (E-adrenoceptor agonist, decongestant) or the asthma medication terbutaline (agonist of $\beta$-adrenoceptors) can be used to treat ischemic priapism. However, only a few studies have shown a persuasive success of this type of treatment. Oral pseudoephedrine, 60-120 mg orally has been suggested as a conceivable therapy due to its alpha-agonist effect. The precise efficacy of this medication's oral use is not well studied [8]. The use of terbutaline orally, at a dose of 5-10 mg, followed by another 5-10 mg 15 minutes later, if required, produces detumescence in 36\% of patients who had prostaglandin-induced priapism [9]. This treatment is appropriate when preparing the infusion. In the following study there is a report on oral administration of terbutaline (2.5-5 mg) in the treatment of recurrent idiopathic priapism [10].

\begin{tabular}{|c|c|c|}
\hline $\begin{array}{c}\text { Duration of One-sided } \\
\text { shunting after Winter } \\
\text { (minutes) }\end{array}$ & $\begin{array}{c}\text { Recurrence } \\
\text { of priapism }\end{array}$ & $\begin{array}{c}\text { Persistent ED } \\
\text { during 6-month } \\
\text { monitoring }\end{array}$ \\
\hline 45 & - & 1 \\
\hline 40 & - & 1 \\
\hline 45 & - & 1 \\
\hline 40 & - & 1 \\
\hline 35 & - & - \\
\hline 30 & - & - \\
\hline 40 & - & - \\
\hline 40 & - & 1 \\
\hline 35 & - & 1 \\
\hline 40 & - & 1 \\
\hline
\end{tabular}


In five patients priapism was completely cured during 30 minutes after administration of $5 \mathrm{mg}$ terbutaline per os.

Also its must be remembered that beta-agonists should be prescribed with caution in individuals with severe angina pectoris, since subsequent acceleration of hemocirculation can cause depletion of potassium $\left(\kappa^{+}\right)$, which may later provoke tachycardia and pulmonary edema.

If after oral or intravenous medication use no detumescence occurs within 30 minutes, the next step is intracavernous vasoactive substances injections. Presently there are a few intracavernous vasoactive substances for the treatment of priapism: metaraminol or agonists of E-adrenoceptors - phenylephrine, norepinephrine, ethylephrine and epinephrine - all with a similar mechanism of action [9-13]. Alpha-agonists exert a vasoconstrictive action on smooth muscle tissue. The literature data demonstrate that for all patients with ischemic priapism, resolution occurred in $81 \%$ of cases treated with epinephrine, 70\% with metaraminol, 43\% with norepinephrine, and 65\% with phenylephrine [14]. The complications of intracavernous injections could be the following: pain, hematoma, infection, and fibrosis of the penis [13]. To prevent the occurrence of complications, the medication must only be injected into a fully erect penis [15]. Local application of above-mentioned medications can lead to systemic complications - increase of blood pressure up to $200 \mathrm{mmHg}$ and hemorrhagic stroke [16, 17]. In patients with high risk of cardiovascular pathologies, electrocardiogram and blood pressure monitoring are strongly recommended during priapism medication.

There are recent works describing use of methylene blue (MB) in order to increase the efficacy and safety of non-invasive therapeutic procedures with minimal side effects and complications [18, $19,20]$. Methylene blue, a guanylate cyclase inhibitor, is a potential inhibitor of endothelial mediated cavernous relaxation and has been used for the treatment of priapism. Its efficacy for the treatment of priapism secondary to intracavernous drugs was generalized by Martinez $H$. et al. $[19,21]$. This pharmacological agent counteracts relaxation of cavernous smooth muscle tissue, causing detumescence. A perspective option is intracavernous administration of $M B$ in the treatment of priapism, since its toxicity and systemic influence is less than in E-adrenergic agents, which are widely used [20]. Using this method, DeHoll et al. first treated 11 patients with priapism by aspirating up to $200 \mathrm{ml}$ cavernous blood and then injecting $50 \mathrm{mg}$ of MB over 3 to 5 minutes [18]. The MB was then also aspirated and the penis was gently squeezed for over 5 minutes. In $67 \%$ of patients, immediate detumescence was noted. Thus, detumescence was found in 100\% patients in whom priapism was caused by intracavernous injection therapy (prostaglandin E1). However, taking into consideration the data of the last research presented by Mejean et al., we do not recommend administration of $\mathrm{MB}$ in the presence of cavernous fibrosis, for example in patients with repeated priapism [22].

Priapism due to sickle-cell anemia is often successfully managed by rehydration, alkalization, analgesia, and hemodilution, which are the main treatment modalities in this case; however, in patients with a sickle-cell disease or hematologic malignancy, systemic treatment of the underlying disorder should not be undertaken as the only treatment for ischemic priapism. Ischemic priapism requires specific oral or intracavernous treatment, which should be administered concurrently with the systemic treatment for hematologic pathology [14]. So, if medical measures are not sufficient, surgical treatment should be performed in these cases [23,24].

Studies on efficacy of gonadotropin-releasing hormone analogues have been conducted, including the use of an antiandrogenic substance (flutamide) in prolonged treatment of recurrent priapism [25].
Despite various pharmacological therapies available for priapism, surgical management is often required if medical therapy is ineffective. There are a large variety of operative treatment modalities:

- distal cavernoglanular shunting: shunting after Winter, shunting after Ebbehoj or Al-Ghorab technique - excising of a piece of the tunica albuginea at the tip of the corpus cavernosum [26];

- anastomosis between a cavernous body and a superficial femoral vein known as shunting after Grayhack;

- cavernospongious (corporospongiosal) shunt (i.e. Quackels technique);

- proximal ligation of the internal pudendal artery;

- shunting of the dorsal cavernous vein, incisions;

- irrigation and drainage of cavernous sinuses;

- percutaneous blood aspiration from cavernous bodies;

- removal of pudendal nerves from the ischiocavernous muscle;

- amputation of the penis if priapism is related to a neoplasm of the penis, etc. $[14,27]$.

In our opinion, shunting after Winter is minimally traumatic among the all surgical methods of ischemic priapism treatment and is successful in the majority of cases. That is why we used this procedure in our patients.

A distal cavernoglanular shunt after Winter is most frequently performed, because this method is effective and creates a connection between, both, the glans penis and tumescent cavernous body [26]. The success rate of the procedure varies between $50 \%$ and $65 \%$ [28]. Complications after such kind of intervention include cavernitis with abscess formation, injury of urethra with stricture or external fistula formation, hematoma with or without thrombosis, and subsequent development of ED in 50\% of patients [29]. Therefore, shunting should be performed only after failure of medical treatment [6]. Proximal shunting using Grayhack or Quackels technique may be performed if more distal shunting procedures have failed to achieve detumescence. The summary data presented by Montague D.K. et al. show resolution rates of 77\% for Quackels, 76\% for Grayhack, 74\% for Al-Ghorab, 73\% for Ebbehoj, and 66\% for Winter procedures, but these rates significantly depend on patients selection. ED rates are less for distal shunts (approximately 25\%) than for the proximal shunts, Quackels and Grayhack, (about $50 \%$ ) [14]. If subsequent ED developed, the method of choice is a phallografting [30].

Repeated painful priapism always needs precision tactics. Taking into consideration frequent failures of open surgeries and their short-term effectiveness, Bastuba et al. have studied the efficacy of selective penile arterial embolization (SPAE) [16]. Using SPAE normal erectile function was restored in $86 \%$ of patients during 5-months, depending on the duration of thrombus disintegration. The authors recommend application of SPAE as a successful surgery in cases of non-ischemic priapism that developed due to injury or arteriovenous fistulas.

\section{CONCLUSIONS}

1. Priapism is viewed as an emergency urological condition that requires a rapid and consistent therapeutic approach. In all cases, the treatment of priapism has to be initially pharmaceutical, which can be converted to surgical treatment as needed.

2. An obligatory condition of priapism management is definition as either ischemic (low flow) or non-ischemic (high flow) type because the treatment approaches and outcomes for these two types are significantly different.

3. According to our data, priapism as a complication after intracavernous administration of prostaglandin E1 occurs in $2.7 \%$ of patients, after additional administration of prostaglandin E1 and 
phentolamine - in 5\% patients, after administration of papaverine - in $8.3 \%$ patients.

4. Unilateral transcaputal puncture of cavernous body (shunting after Winter) in our patients with ischemic priapism allowed to achieve detumescence in 100\% of cases without subsequent recurrence.

\section{REFERENCES}

1. Hauri D, Spycher M, Bruhlmann W: Erection and priapism: a new pathophysiological concept. Urol Int 1983: 88: 138-145.

2. Spycher MA, Hauri D: The ultrastructure of the erectile tissue in priapism. J Urol 1986; 135: 142-147.

3. Pohl J, Pott B, Kleinhans G: Priapism: a three-phase concept of management according to etiology and prognosis. Br J Urol 1986; 58: 113-118.

4. Van Der Horst C, Stuebinger $\mathrm{H}$, Seif $\mathrm{C}$ et al: Priapism: etiology, pathophysiology and management. Int Bras J Urol 2003; 29 (5): 391-400.

5. El-Bahnasawy MS, Dawood A, Farouk A: Low-flow priapism: risk factors for erectile dysfunction. BJU Int 2002; 89: 285-290.

6. Bertram RA, Webster GD, Carson CC: Priapism: etiology, treatment and results in series of 35 presentations. Urology1985; 26: 229-232.

7. Martínez Portillo FJ, Juenemann KP: New aspects in the treatment of priapism. Andrologia 1999; 31: 53-58.

8. Liguori G, Bucci S, Benvenuto B et al: Priapism: pathophysiology and management. J Androl Sci 2009; 6: 13-20.

9. Lowe FC, Jarow JP: Placebo-controlled study of oral terbutaline and pseudoephedrine in management of prostaglandin E1-induced prolonged erections. Urology 1993; 42: 51-53.

10. Shanta TR, Finnerty DP, Rodriguez AP: Treatment of persistent penile erection and priapism using terbutaline. J Urol 1989; 141: 1427-1429.

11. Koga S, Shiraishi K, Saito Y: Post-traumatic priapism treated with metaraminol bitartrate: case report. J Trauma 1990; 30: 1591-1593.

12. Lue TF, Tanagho EA: Physiology of erection and pharmacological management of impotence. J Urol 1987; 137: 829-836.

13. Sidi AA: Vasoactive intracavernous pharmacotherapy. Urol Clin North Am 1988; 15: 95-101.

14. Montague DK, Jarow J, Broderick GA et al: American Urological Association guideline on the management of priapism. J Urol 2003; 170 (4 Pt 1): 1318-1324.

15. Potempa D, Juenemann KP, Schuller A et al: Die Therapie der prolongierten Erektion. Akt Urol 1991; 143: 933-935.

16. Bastuba MD, Saenz de Tejada I, Dinlenc CZ et al: Arterial priapism: diagnosis, treatment and long-term followup. J Urol 1994; 51: 1231-1237.
17. Rösener M, Wechsel HW, Dichgans J: Intrazerebrale Massenblutung nach intrakavernöser Metaraminol-Behandlung einer prolongierten. Erektion Akt Urol 1995; 26: 427-430.

18. DeHoll JD, Shin PA, Angle JF et al: Alternative approaches to the management of priapism. Int J Imp Res 1998; 10: 11-14.

19. Martinez Portillo FJ, Hoang-Böhm J, Weiss J et al: Methylene blue as a successful treatment alternative for pharmacologically-induced priapism: Eur Urol 2001; 39: 20-23.

20. Steers WD, Selby JB: Use of methylene blue and selective embolization of the pudendal artery for high flow priapism refractory to medical and surgical treatment. J Urol 1991; 146: 1361-1363.

21. Martinez Portillo FJ, Fernandez Arancibia MI, Bach S et al: Methylene blue: an effective therapeutic alternative for priapism induced by intracavernous injection of vasoactive agents. Arch Esp Urol 2002; 55: 303-305.

22. Mejean A, Marc B, Rigot JM, Mazeman E: Letter to the editor. J Urol 1993; 149: 1149.

23. Melman A, Serels S: Priapism. Int J Imp Res 2000; 12 (Suppl. 4): 133-139.

24. Rogers ZR: Priapism in Sickle Cell Disease. Hematol Oncol Clin North Am 2005; 19, Issue 5: 917-928.

25. Levine LA, Guss SP: Gonadotropin-releasing hormone analogues in the treatment of sickle cell anemia-associated priapism. J Urol 1993; 150: 475-477.

26. Winter CC: Priapism treated by modification of creation of fistulas between glans penis and corpora cavernosa. J Urol 1979; 121: 743-744.

27. Broderick GA, Kadioglu A, Bivalacqua TJ et al: Priapism: pathogenesis, epidemiology, and management. J Sex Med 2010; 7 (1 Pt 2): 476-500.

28. Winter CC, McDowell G: Experience with 105 patients with priapism: update review of all aspects. J Urol 1988; 140: 980-983.

29. Parivar F, Lue TF: Priapism, In: Hellstrom WJG (ed): Male Infertility and Sexual Dysfunction, Berlin, Springer-Verlag 1997, pp. 401-408.

30. Kabalin JN: Corporeal fibrosis as a result of priapism prohibiting function of self-contained inflatable penile prosthesis. Urology 1994; 43: 401-403.

\section{Correspondence}

Alexander Shulyak

6, Boguna Street

Apt. 6, Lviv 79013, Ukraine

phone: +380676708952

sasha@meduniv.lviv.ua 